\title{
Proceeding
}

7th INSHS International Christmas Sport Scientific Conference, 9-12 December 2012. International Network of Sport and Health

Science. Szombathely, Hungary

\section{Moderate and vigorous physical activity in the $55+$ teachers' daily routine}

\author{
JUDIT EKLER ${ }^{1} \quad$, KATALIN NAGYVÁRADI ${ }^{1}$, BEATRIX KISS-GEOSITS ${ }^{1}$, TAMÁS CSÁNYI² \\ ${ }^{1}$ University of West Hungary, Savaria Campus, Szombathely, Hungary \\ ${ }^{2}$ Eötvös Loránd University, Faculty of Primary and Pre-School Education, Budapest, Hungary
}

\begin{abstract}
Ekler J, Nagyváradi K, Kiss-Geosits B, Csányi T. Moderate and vigorous physical activity in the 55+ teachers' daily routine. J. Hum. Sport Exerc. Vol. 8, No. Proc2, pp. S204-S210, 2013. The health of teachers aged over 50 is endangered by several risk factors related to the age and today's social conditions. We have researched the level of moderate and vigorous physical activity (MVPA), which is regarded as a health protective factor; and the relationship between physical activity and health status in the daily routine of senior teachers. Our sample consisted of 21 teachers, aged 52-65. The data, which shows their physical activity, was recorded, with the help of the Actigraph GT3X+ triaxial accelerometer and a log about their daily routine. The actual physical condition was assessed with the help of InBody720 body composition analyser and CardioVision 2000 oscillometric blood pressure monitor. For comparing the parameters of the activity level and health condition the Paired Samples T Test was applied; for finding correlations we used correlation analysis. We found that the values of men's average energy usage and of MVPA are significantly higher than women's ones. The values of the number of steps per minute are significantly lower in the case of 10 kilos of excess body weight. $81 \%$ of the researched sample reached the weekly minimum (150 minutes) via their weekly activities, which is considered to be a protective MVPA factor. Those ones who did less MVPA activities than this are regarded to belong to the endangered health category, as a tendency. The senior teachers reach the MVPA - that is regarded as the protective factor of health status - via activities, which are related to daily transport, housekeeping, education and sporting. With the minor exception of P.E. teachers, lifestyle changes are mostly suggested to those ones who have 10 kilos of excess body weight. Key words: ACCELEROMETER, MVPA, HEALTH PROTECTIVE FACTOR.
\end{abstract}

\footnotetext{
Corresponding author. Károlyi G. tér 4, Postal Code: 9700 , Szombathely, Hungary

E-mail: hekler@mnsk.nyme.hu

7th INSHS International Christmas Sport Scientific Conference, 9-12 December 2012. International Network of Sport and Health Science. Szombathely, Hungary.

JOURNAL OF HUMAN SPORT \& EXERCISE ISSN 1988-5202

(c) Faculty of Education. University of Alicante

doi:10.4100/jhse.2012.8.Proc2.23
} 


\section{INTRODUCTION}

In the past years many researches came up about PA like a health protecting factor. The researchers studied the effect of moderate or vigorous PA on the health by healthy and by sick people as well. For example Chomistek et al. (2011) found that 3 hours vigorous PA weekly can decrease the risk of infarction by 22 per cent in the case of men. Woodcock et al (2010) found that 7 hours moderate PA weekly can decrease the mortality risk by 24 per cent. Based on the researches, it can be said that the health protecting effect can be resulted by any moderate physical activities done on a weekly basis and which take more than 10 minutes per occasion (Manson et al., 2002; Orsini et al., 2008).

As a result of the worrying decline in the population's health condition, many nations have worked out health proposals, which are based on the formerly mentioned scientific findings (Physical Activity Guidelines for Americans). The proposals set the minimum value of the preventive PA either in time (150 $\mathrm{min} /$ week MPA or $75 \mathrm{~min} /$ week VPA) or in step number (8.000 - 10.000 steps/day). As for an additional criterion of the preventive effect, the PA should be evenly distributed across the week.

In our work we researched a special group that is the 55+ teachers' daily routine activities. Our aim was to define whether the researched senior teachers reach the amount of health prevention PA in their daily routine and whether direct correlation between their PA and health condition can be detected or not.

We also studied the features of PA in order to be able to formulate personal proposals.

\section{MATERIAL AND METHODS}

\section{Participants}

The sample consisted of 21 teachers, aged $52-65$ (mean $=57.7 \pm 5.35$ years). We measured and observed 7 male teachers and 14 female teachers from universities ( $n=9$, male $=5$, female $=4$ ) and secondary schools $(n=12$, male $=2$, female $=10) .42 .85 \%$ of the sample (9 members) was P.E. teachers. Most participants of our research are active teachers. The 21 -member-sample covers the $31.4 \%$ of teachers of that age group in Szombathely.

We note here that they joined the research voluntarily after they had received our written request. It means that the members of the sample mainly consist of the health conscious senior teachers.

\section{Measures}

We collected data about the teacher's health condition and about the level of their PA. The actual physical condition was assessed with the help of InBody720 body composition analyzer and CardioVision 2000 oscillometric blood pressure monitor. The InBody 720 is adapted to measure the muscle/fat rate, visceral fat, to make weight control, and to get a health diagnosis (normal, alert, risky) too. The CardioVision 2000 monitor is adapted to show the state of the vascular system. The ASI range (the arterial stiffness index) can mark the health status (normal, risky) too.

The data, which shows our sample's physical activity, was recorded through combined data collection, as the international background literature suggests it (Woodcock et al., 2010); with the help of the Actigraph GT3X+ triaxial accelerometer and a completed log about their daily routine. The Actigraph GT3X+ triaxial accelerometer is a small sensor, which can measure the moving in all direction and the duration of the moving, as well. 


\section{Procedures}

The actual physical condition was assessed at the beginning of the study. The measurement results were individually discussed. The test subjects put on the Actigraph GT3X+ after their actual health condition had been examined. The teachers wore the sensor on their right hip, all day long through 7 days, except the night and shower. We identified the days as valid, if the observed person wore the accelerometer for 8 hours. The teachers were completing a daily physical activity log on a one hour scale during the research.

After finishing the research period, the experiences were interpreted by individual consultations and the subjects were given some lifestyle advice.

\section{Analysis}

For data analysis by Actigraph GT3X+ we chose 60 secs. epoch time (Cain \& Geremia, 2011). For the analysis of their energy usage we set the Freedson (2011) type of Vector magnitude algorithm. We determined the cut point values along the threshold values of Vector Magnitude Sasaki, John and Freedson (2001), which is designed for adults. The numbers of 10-min bouts above the MVPA threshold were also used to construct another outcome variable.

For comparing the parameters of the activity level and health condition the Paired Samples T Test was applied; for finding correlations we used correlation analysis (Spearman). Statistical significance was set at $P<0.05$ in all analyses. The statistical analyses were conducted with SPSS software.

\section{RESULTS}

Actual health condition of the teachers

The sample was put into three health categories, based on the health classification of InBody720 body composition analyzer and CardioVision 2000 oscillometric blood pressure monitor (Table 1). According to both instruments, $28.6 \%(n=6)$ of the sample belongs to the normal health category. In the case of $38.1 \%$, one of the health condition categorization is normal; the other one is alert or risky. $33.3 \%(n=7)$ of the sample is alert or risky according to both instruments.

Table 1. Teachers' health category by InBody720 and CardioVision 2000

\begin{tabular}{|c|c|c|c|c|c|}
\hline & & & \multicolumn{2}{|c|}{ Pattern category } & \multirow[b]{2}{*}{ Total } \\
\hline & & & normal & risky & \\
\hline Life pattern & normal & Count & 6 & 0 & 6 \\
\hline \multirow[t]{5}{*}{ In-body } & & $\%$ of Total & 28.6 & 0 & 28.6 \\
\hline & alert & Count & 6 & 3 & 9 \\
\hline & & $\%$ of Total & 28.6 & 14.3 & 42.9 \\
\hline & risky & Count & 2 & 4 & 6 \\
\hline & & $\%$ of Total & 9.5 & 19.0 & 28.6 \\
\hline \multirow[t]{2}{*}{ Total } & & Count & 14 & 7 & 21 \\
\hline & & $\%$ of Total & 66.7 & 33.3 & 100.0 \\
\hline
\end{tabular}


Among the risk factors, which can be registered by both instruments, teachers in the sample are mostly concerned in excess body weight. $43 \%$ of them $(n=9)$ have more than 10 kilos of excess, $19 \%$ of them $(n=4)$ have between 5 to 9.9 kilos of extra weight (Figure 1).

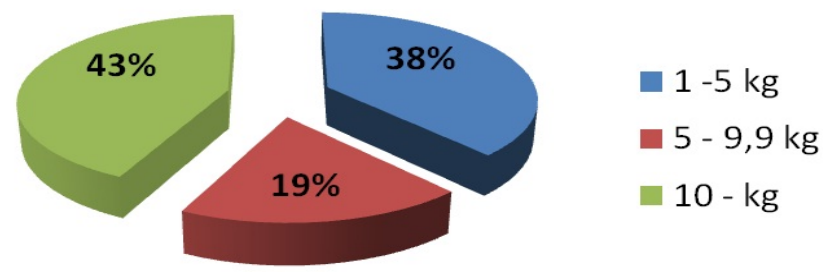

Figure 1. Teachers' excess weight compared to the ideal weight, in kilograms

\section{Features of the teachers' $P A$}

Regarding the daily routine of the teachers, the mean time of moderate and vigorous PA is $261.67 \mathrm{~min}$. Its minimum value is $75 \mathrm{~min}$, the maximum one is $484 \mathrm{~min}$ and the value of the median is $229 \mathrm{~min}$ (Figure 2.). The values of men's average energy usage $(p=.002 ; F=, 769 ; d f=20)$ and of MVPA $(p=.017 ; F=034 ; d f=20)$ are significantly higher than women's ones.

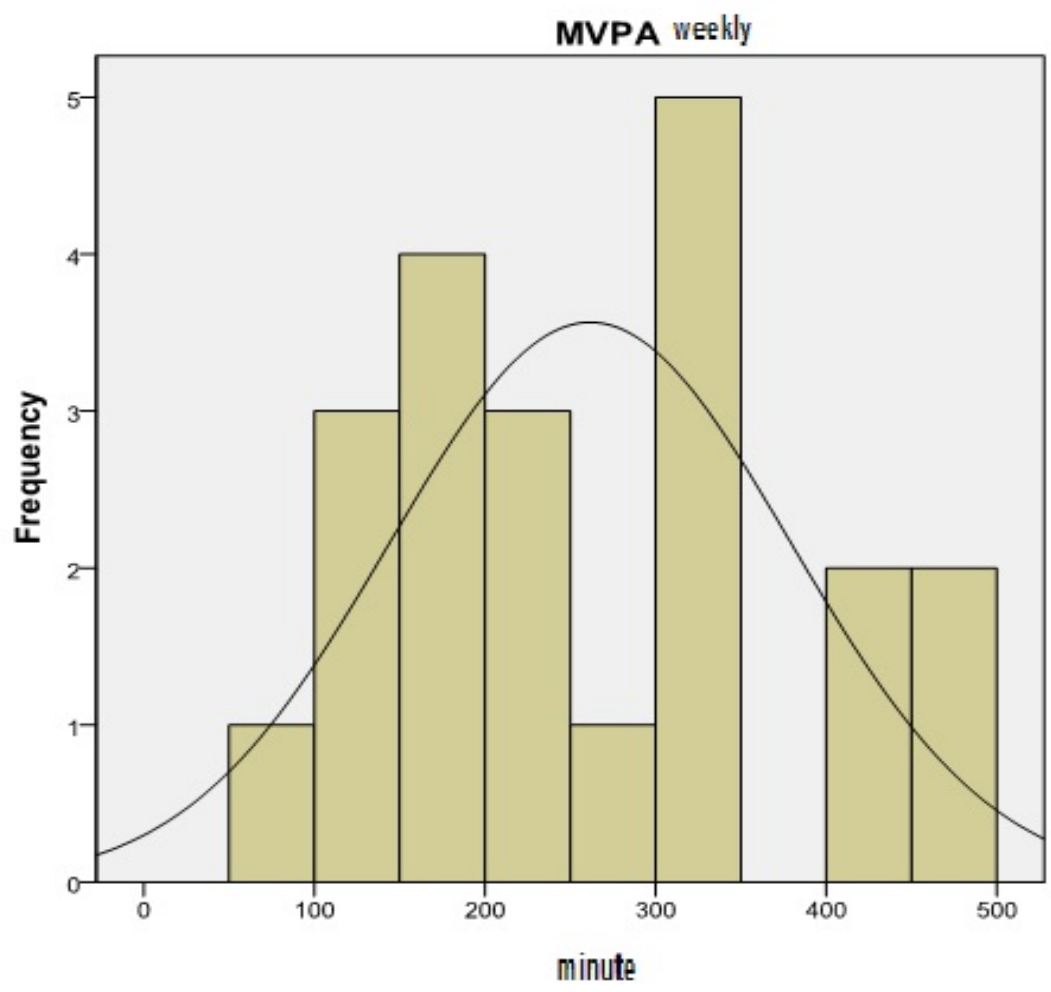

Figure 2. Teachers' weekly MVPA 
The count of steps' (daily by accelerometer-determined) mean is 8499.48 , the value of the median is 9181.0. Its minimum value is 3721 , the maximum is 13379 (Figure 3.). The values of the number of steps per minute are significantly lower in the case of 10 kilos of excess body weight $(p=.011 ; F=.029 ; d f=11)$.

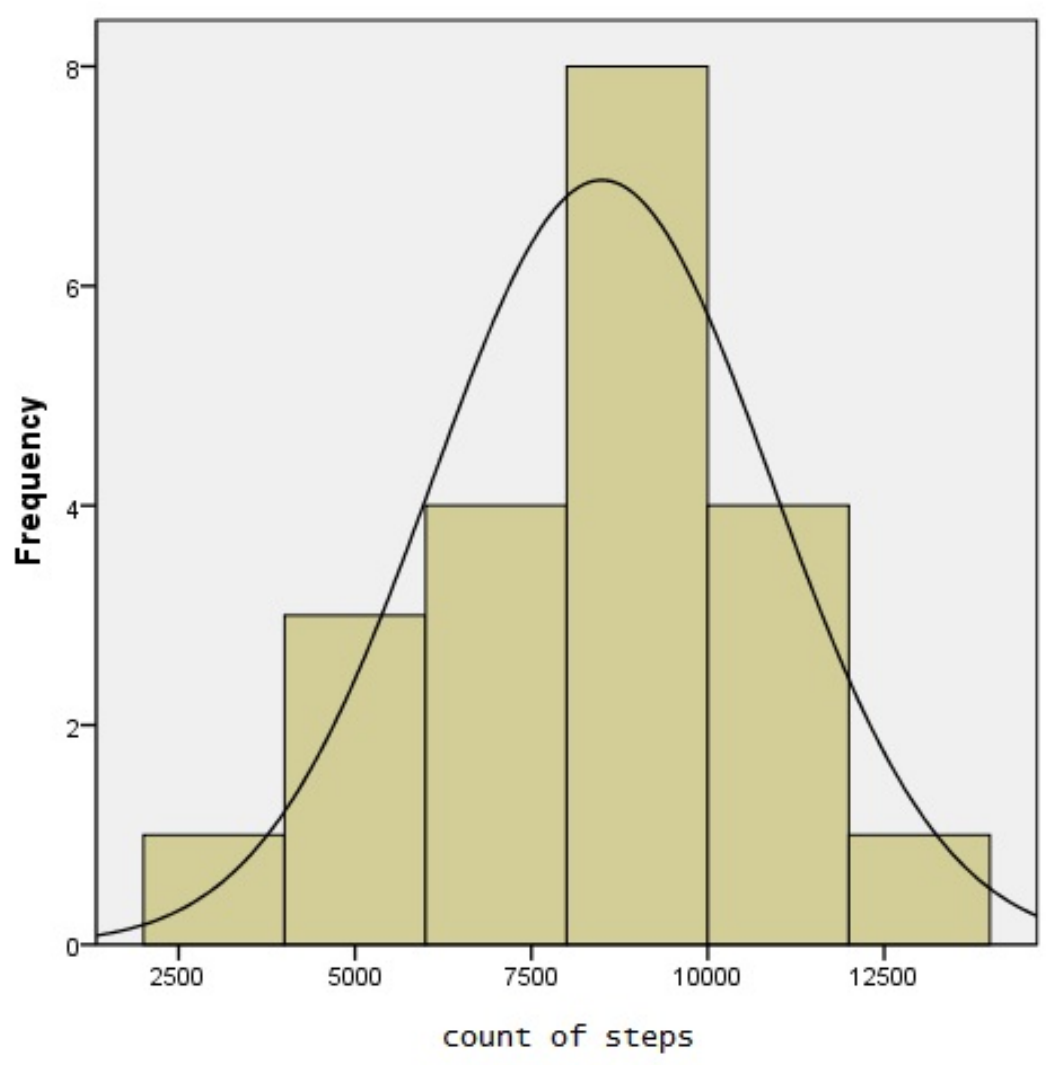

Figure 3. Teachers' count of steps (daily)

$81 \%$ of our sample complete the recommendations by health programs, and do 150 minutes of MVPA weekly. $42.9 \%$ of the sample do over 300 min of MVPA per week. The research subjects reached that level of physical activity, which can be assessed from health preventive point of views (light metabolic equivalents $=3 \mathrm{METs}$ ) by means of commuting, shopping, school education. These activities implied moderate (3-6 METs) physical activity in many cases. The moderate (3-6 METs) physical activity could be reached by biking, walking the dog and doing some gardening. The vigorous (6-9 METs) physical activity could be achieved by sport activities (running, playing tennis, basketball, football, etc.)

The average time of physical activity which is over 3 METs means 16.121 minute/Bout (median 15.40 minute/Bout). Its minimum value is 10.80 minute/Bout, its maximum value is 23.70 minute/Bout. On a daily average, the number of Bouts is 1.67 (minimum 0.16, maximum 3.0, median 1.4). These data are shown in Figure 4. 


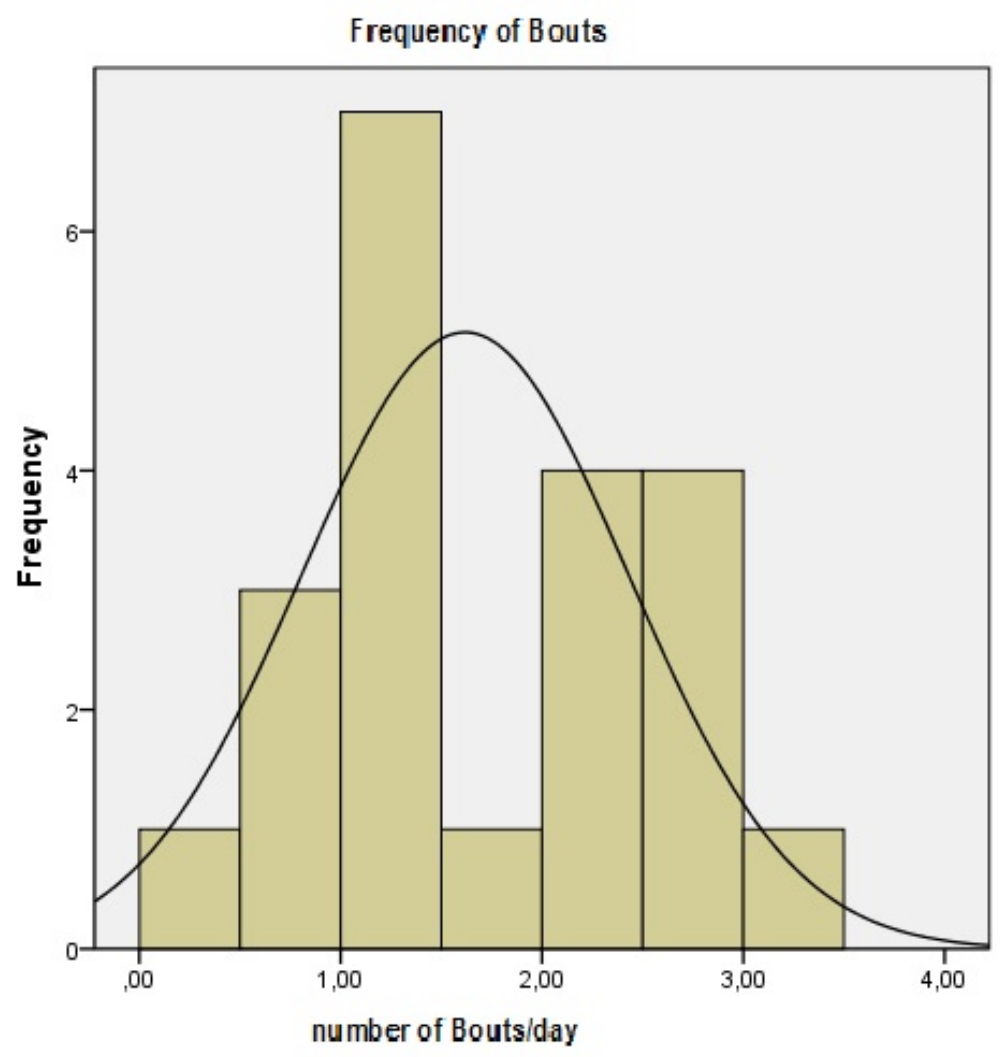

Figure 4. The number of Bouts/day

\section{DISCUSSION}

Although the small data population and its selection limit the external validity of the data, there are a number of definite conclusions that can be made from these findings.

The primary finding of this study is that those teachers who does more physical activities in their daily routine than the minimum level, which is enough for health preventive purposes (150 minutes/week), have better health conditions, as a tendency $(F=41.6 ; d f=13 ; p=.131)$. However, it is only true in the case when the period of time of the mentioned 'more than 150min/week MVPA' covers more than 10 minutes per occasion, and the activities are done systematically during the week. Regarding merely the amount of MVPA and the actual health status, there is no significant connection, even not in those cases when the weekly MVPA have reached the 300 minutes $(p=.893)$.

Our results - similarly to the results of other researches (Gutin et al., 2005) - show the excess weight as a dominant risk factor. More than 10 kilos of extra body weight affects the physical activity negatively. People with more than 10 kilos of excess weight tend to move significantly less (less frequently per week and less period of time per occasion) and with a significantly lower intensity $(F=.629$; $d f=11 ; p=.011)$. The overweight occurs primarily in the visceral fat. Its larger amount is associated with significantly lower MVPA $(F=.420 ; d f=9 ; p=.033)$. 
Sport activities and the resulted VPA characterise mainly the Physical Education teachers. Naturally, those sport activities are recommended which are leading to VPA.

However, the positive experience of the research is those activities in the daily routine, which are related to work, transport or household can also result in an MPA, which corresponds to the health protective factor. This moderate (3-6 METs) physical activity can be also reached safely even by members of the senior age group who tend to work out less, and do sport activities less frequently. However, it is important that performing moderate (3-6 METs) physical activities for 4-5 minutes does not result health preventive effects. In order to reach the health preventive effect, minimum 10 minute-long periods and weekly frequency is needed. With the minor exception of P.E. teachers, lifestyle changes are mostly suggested to those ones who have 10 kilos of excess body weight.

\section{REFERENCES}

1. CHOMISTEK AK, CHIUVE SE, JENSEN MK, COOK NR, RIMM EB. Vigorous Physical Activity, Mediating Biomarkers, and Risk of Myocardial Infarction. Med Sci Sports Exerc. 2011; 43(10): 1884-1890.

2. CAIN L, GEREMIA M. Accelerometer Data Collection and Scoring Manual, For Adult \& Senior Studies. San Diego State University, James Sallis Active Living Research Lab. 2011.

3. GUTIN B, YIN Z, HUMPHRIES MC, BARBEAU P. Relations of moderate and vigorous physical activity to fitness and fatness in adolescents. The American Journal of Clinical Nutrition. 2005; 81(4): 746-50.

4. ISHIKAWA-TAKATA K, TABATA I. Exercise and Physical Activity Reference for Health Promotion 2006 (EPAR2006). J Epidemiol. 2007;17(5): 177.

5. MANSON JE, GREENLAND P, LACROIX AZ, STEFANICK ML, MOUTON CP, OBERMAN A, PERRI MG, SHEPS DS, PETTINGER MB, SISCOVICK DS. Walking compared with vigorous exercise for the prevention of cardiovascular events in women. N Engl J Med. 2002; 347(10): 716725.

6. ORSINI N, MANTZOROS CS, WOLK A. Association of physical activity with cancer incidence, mortality, and survival: a population-based study of men. British Journal of Cancer. 2008; 98(11): 1864-9.

7. Physical

http://www.health.gov/paguidelines/guidelines/default.aspx (13-03- 2012)

Americans

(2008)

8. SASAKI JE, JOHN D, FREEDSON PS. Validation and comparison of ActiGraph activity monitors. $J$ Sci Med Sport. 2011; 14(5): 411-416.

9. WOODCOCK J, FRANCO OH, ORSINI N, ROBERTS I. Non-vigorous physical activity and allcause mortality: systematic review and meta-analysis of cohort studies. Int J Epidemiol. 2011; 40(1):121-138. 